\title{
Thermal mapping as a valuable tool for road weather forecast and winter road maintenance: an example from the Italian Alps
}

Book or Report Section

Published Version

Todeschini, I., Di Napoli, C., Pretto, I., Merler, G., Cavaliere, R., Apolloni, R., Antonacci, G., Piazza, A. and Benedetti, G. (2016) Thermal mapping as a valuable tool for road weather forecast and winter road maintenance: an example from the Italian Alps. In: Themistocleous, K., Hadjimitsis, D. G., Michaelides, S. and Papadavid, G. (eds.) Fourth International Conference on Remote Sensing and Geoinformation of the Environment. SPIE Proceedings, 9688. SPIE Press, United States, $96880 \mathrm{H}$. doi: https://doi.org/10.1117/12.2240484 Available at https://centaur.reading.ac.uk/69453/

It is advisable to refer to the publisher's version if you intend to cite from the work. See Guidance on citing.

To link to this article DOI: http://dx.doi.org/10.1117/12.2240484

Publisher: SPIE Press 
copyright holders. Terms and conditions for use of this material are defined in the End User Agreement.

\section{www.reading.ac.uk/centaur}

\section{CentAUR}

Central Archive at the University of Reading

Reading's research outputs online 


\title{
Thermal mapping as a valuable tool for road weather forecast and winter road maintenance: An example from the Italian Alps
}

\author{
Ilaria Todeschini ${ }^{\mathrm{a}}$, Claudia Di Napoli ${ }^{\mathrm{b}}$, Ilaria Pretto ${ }^{{ }^{c}}$, Giacomo Merler ${ }^{\mathrm{c}}$, Roberto Cavaliere ${ }^{\mathrm{d}}$, \\ Roberto Apolloni ${ }^{\mathrm{e}}$, Gianluca Antonacci ${ }^{\mathrm{a}}$, Andrea Piazza ${ }^{\mathrm{b}}$, Guido Benedetti ${ }^{\mathrm{c}}$ \\ ${ }^{a}$ CISMA Srl, via Siemens 19, Bolzano, Italy; ${ }^{b}$ Meteotrentino Weather Service, Autonomous \\ Province of Trento, via Vannetti 41, Trento, Italy; ${ }^{\mathrm{c}} \mathrm{Road}$ Management Service, Autonomous \\ Province of Trento, via Gazzoletti 33, Trento, Italy; ${ }^{\mathrm{d} I D M}$ Südtirol/Alto Adige, via Siemens 19, \\ Bolzano, Italy; ${ }^{\mathrm{e}}$ Famas System S.P.A., Via degli Artigiani Sud 19, Egna, Bolzano, Italy
}

\begin{abstract}
During the winter period ice is likely to form on roads, making pavement surfaces slippery and increasing accident risk. Road surface temperature (RST) is one of the most important parameters in ice formation. The LIFE+ "CLEANROADS" project aims to forecast RSTs in advance in order to support road maintenance services in the timely and effective preparation of preventive anti-icing measures. This support is provided through a novel MDSS (Maintenance Decision Support System). The final goal of the project is to quantitatively demonstrate that the implemented MDSS is capable to minimize the consumption of chemical anti-icing reagents (e.g. sodium chloride) and the associated environmental (water and air) impact while maintaining the current high levels of road safety.

In the CLEAN-ROADS system RSTs have been forecast by applying the numerical model METRo (Model of the Environment and Temperature of Roads) to a network of RWIS (Road Weather Information System) stations installed on a test route in the Adige Valley (Italy). This forecast is however local and does not take into account typical peculiarities along road network, such as the presence of road sections that are particularly prone to ice formation. Thermal mapping, i.e. the acquisition of mobile RST measurements through infrared thermometry, permits to (i) identify and map those sections, and (ii) extend the forecast from a RWIS station to adjacent areas. The processing of thermal mapping signals is however challenging because of random variations in the road surface emissivity. To overcome this we have acquired several thermal mapping traces along the test route during winter seasons 2014-2015 and 2015-2016. We have then defined a "characteristic" thermal fingerprint as a function of all its historical thermal mapping signals, and used it to spatialize local METRo forecasts. Preliminary results suggest the high potential of such a technique for winter road applications.
\end{abstract}

Keywords: Thermal mapping, Road surface temperature, Road ice hazard, Meteorological forecast, Winter road maintenance

\section{INTRODUCTION}

When road temperatures get close to freezing point $\left(0^{\circ} \mathrm{C}\right)$ in winter time, road engineers and maintenance authorities have to decide whether, where and when to spread anti-icing salt on roads in order to prevent road ice formation and, consequently, hazardous slippery pavements. This is the main concept at the basis of CLEAN-ROADS, a pilot project launched in late 2012 in the Autonomous Province of Trento, Italy. Co-funded by the LIFE+ program of the European Commission, the CLEAN-ROADS project aims at introducing an innovative MDSS (Maintenance Decision Support System) to optimize winter road treatments and minimize the environmental impact produced by chemical deicer on the surrounding environment ${ }^{1}$.

* ilaria.pretto@provincia.tn.it; clean-roads.eu

Fourth International Conference on Remote Sensing and Geoinformation of the Environment (RSCy2016), edited by Kyriacos Themistocleous, Diofantos G. Hadjimitsis, Silas Michaelides, Giorgos Papadavid,

Proc. of SPIE Vol. 9688, 96880H · @ 2016 SPIE · CCC code: 0277-786X/16/\$18 - doi: 10.1117/12.2240484 
Historically, since the mid-80s the maintenance decision process has been supported by the information provided by road weather information systems (RWIS) which consist of automatic road weather stations and road weather forecasts ${ }^{2}$. Road weather stations measure meteorological variables, such as air temperature, relative humidity, wind speed, precipitation; they also provide road surface parameters, namely road surface temperature (RST) and state (dry, wet), through sensors embedded in the pavement. Road weather forecasts, such as the Model of the Environment and Temperature of Roads (METRo) developed by Environment Canada ${ }^{3}$, predict the likelihood of road ice formation from the energy intake and loss at the road surface. As this energy exchange is regulated by environmental and meteorological variables, road weather forecast are based on numerical weather models that are initialized by measurements from RWIS stations.

This approach provides a knowledge that is site-specific and, as such, it might not be representative of the road condition between two or more stations. Sunlight exposure, wind, cloudiness, traffic and other factors make winter night-time road surface temperatures (RSTs) vary by more than $10^{\circ} \mathrm{C}$ along a road ${ }^{4}$. It is therefore mandatory to find a tool that can extract information on RSTs and conditions across an entire road. This tool is thermal mapping. Thermal mapping is a technique that uses an infrared thermometer mounted on a vehicle to detect RST variations along a survey route. RST variations are usually displayed as diagrams, called "fingerprints", where the departure of RSTs from the mean is plotted against the distance sampled by the vehicle ${ }^{4}$. The combination of different fingerprints measured on different routes at the same night represents a "thermal map", i.e. the spatial variations of RSTs across a road network under specific weather conditions $\mathrm{s}^{4}$. With thermal mapping, road weather forecast can be extended from RWIS stations to road stretches (spatialization), reflecting the RST variations in between. Road stretches falling below $0^{\circ} \mathrm{C}$ on a particular night can thus be identified in respect to other stretches remaining above $0^{\circ} \mathrm{C}$. This information can be used by road maintenance authorities to adapt anti-icing strategies accordingly, i.e. to spread salt only when and where weather and road conditions require so. This would reduce maintenance cost and the impact of anti-icing salt on the environment. The use of chemicals such as sodium chloride is of major concern from this point of view. It accelerates the deterioration of road structures and the corrosion of vehicles, it increases the levels of particulate matter in the air and it alters the natural ecosystem (e.g., soil and ground water supplies) near the roadway ${ }^{5}$.

This paper describes the usefulness and value of thermal mapping in road winter maintenance. It first examines the acquisition and analysis of spatial RST variations as measured via thermal mapping along two test routes in the alpine Trentino region, Italy. It then describes the first implementation of acquired fingerprints in METRo road weather forecast model and its potential in predicting "thermal maps" that can assist road engineers and maintenance authorities in their decisions through RWIS.

\section{METHODOLOGY}

\subsection{Study area}

Thermal mapping was carried out in Trentino region, a mountainous area in the Northeast Alps of Italy characterized by severe winter weather. Two different test routes were selected for detailed analysis. The first route is a $14 \mathrm{~km}-\mathrm{long}$ stretch along a state highway (SS12), it is located in a valley bottom (Adige Valley) and it covers residential, industrial and countryside areas (Figure 1, blue route). The second route is $10 \mathrm{~km}$-long stretch along a state highway (SS47) and it develops from the Adige Valley to a higher altitude valley (Valsugana Valley, Figure 1, red route). It also contains a range of different land uses, road types, lane configurations and traffic fluxes. A full dataset of thermal fingerprints were acquired along the first route in winter 2014-2015 and winter 2015-2016, and along the second route in winter 20152016. In addition, specific site measurements on road and atmospheric variables were acquired in the same periods by two automatic road weather stations, located along the selected routes.

\subsection{Equipment}

Thermal mapping RSTs, that is, road thermal fingerprints were obtained by an infrared radiometer set on a survey vehicle tow hook (Figure 2). The radiometer, which is based on thermopile technology, measures the energy flux density emitted by the surface by applying the Stefan-Boltzmann equation ${ }^{6}$. Its optical system is characterized by a field of view equal to $10^{\circ} \mathrm{deg}$ and by a spectral window between 5 and $12 \mu \mathrm{m}$. The infrared sensor has an accuracy of $\pm 1{ }^{\circ} \mathrm{C}$ for measurements performed in a temperature range between $-20^{\circ} \mathrm{C}$ and $+40^{\circ} \mathrm{C}$, and on objects with emissivity equal to 1 . Thermal mapping RSTs were acquired with a maximum frequency of 6 acquisitions per second, ensuring a measurement every $20 \mathrm{~m}$ even with vehicle speed up to $70 \mathrm{~km} / \mathrm{h}$. Measurements were transferred from the sensor board to the vehicle unit through Bluetooth communication. The vehicle unit stored measured values locally and, at the same time, sent 


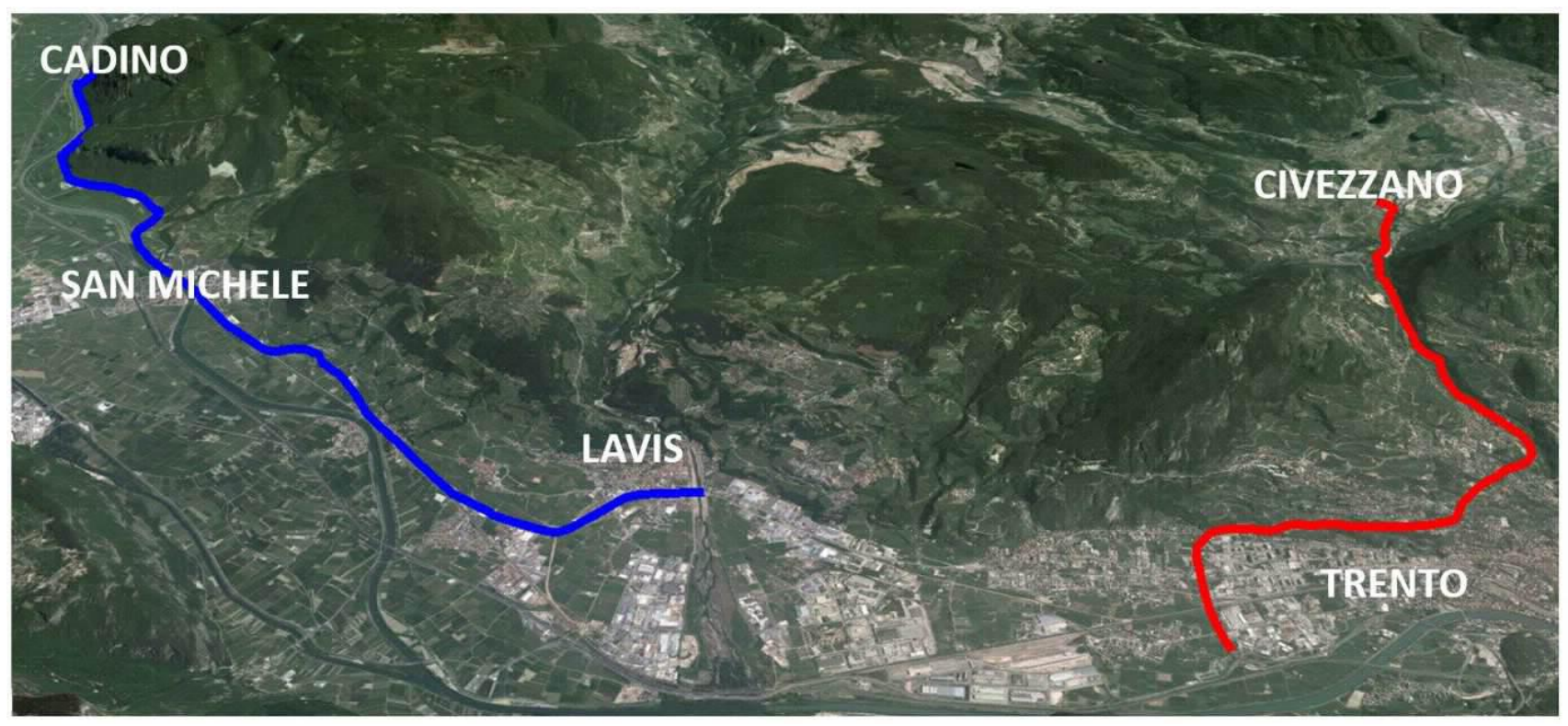

Figure 1. The blue path shows the "Adige Valley" route along the SS12 state highway from Lavis town to Cadino town; the red one shows the "Valsugana Valley" route along the SS47 state highway from Trento city to Civezzano town. Map data (C)2015 Google.

them to the MDSS server via an Internet connection established on the mobile network. This permitted to implement a real-time management for the collected information. The data stream was timely and geographically referenced through a GPS device, which enabled a mapped visualization through standard geographical information system (GIS) tools.

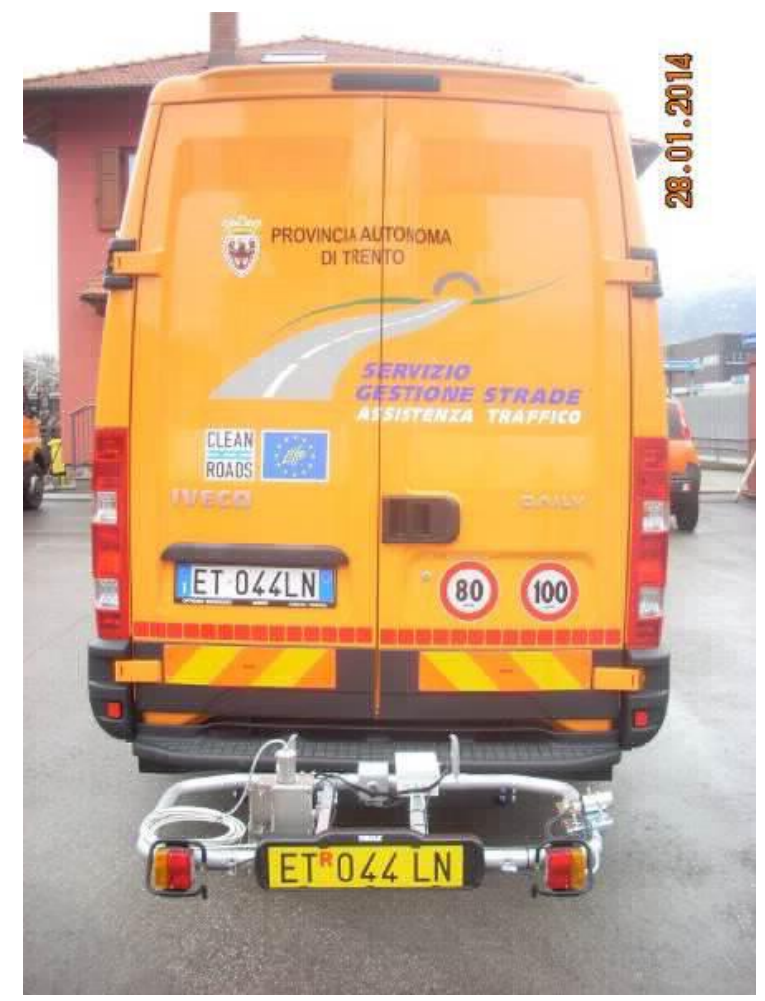

Figure 2. Thermal mapping vehicle. 


\subsection{Meteorological conditions}

Meteorological conditions strongly influence thermal mapping measurements, particularly in a mountainous region as that considered in this study. Meteorological conditions are typically classified as extreme, intermediate or damped ${ }^{7}$. Under extreme conditions, i.e. on stable, clear and calm nights, variations in RST are the greatest and the thermal fingerprint is clearly developed as the sampled road emits infrared radiation (heat) to space and cools down. Under damped conditions, i.e. on overcast, rainy and windy nights, spatial variations in RST are the smallest and the thermal fingerprint is spatially homogeneous because heat is prevented from leaving the surface and the cooling is far less overall. Under intermediate conditions, RST variations have in-between characteristics depending upon the amount of wind and cloud. In order to best identify colder road sections against warmer road sections, thermal mapping was carried out near sunrise (i.e. when RSTs usually reach the lowest values) under extreme conditions, namely wind speed $\leq 2 \mathrm{~m} / \mathrm{s}$ and cloud cover $\leq 1 / 8$. In winter seasons 2014-2015 and 2015-2016, 20 and 10 "extreme" thermal fingerprints were collected along the Adige Valley route and the Valsugana Valley route, respectively. Note that thermal mapping was carried out when (a) extreme conditions had persisted for at least 2-3 hours before sunrise, i.e. on nights with no unsettling weather conditions that could influence RSTs on the short time scale, and (b) the mean RST temperature was below $0^{\circ} \mathrm{C}$ over the entire sampled route.

\subsection{Pre-processing stage: noise removal}

Each measurement acquired via thermal mapping is characterized by a small "signal noise" perturbing acquired data on both the temporal and spatial scale ${ }^{8}$. A signal noise in thermally-mapped RST data might be due to different pavement emissivity (i.e. variations in roughness or color), to the presence of dirty soil on the road surface or to electronic noise, and must be removed in order to correctly identify the thermal fingerprints of the selected routes. A low-pass Gaussian filter has been applied for this purpose ${ }^{9}$. Differently from a common mean filter, a low-pass Gaussian filter removes signal noise without smoothing any gradient associated with a real change in RSTs. Rapid and large scale changes due to discontinuous surface features or topography variables are thus retained, as is the mean of raw thermal data. Different window lengths have been tested for the Gaussian filter before choosing the correct one. Increasing the window length decreases the signal noise, but a too wide window length may reduce real RST changes. The final choice has been to set up the filter window length equal to $200 \mathrm{~m}$. Figure 3 shows an example of thermally-mapped RST data to which a $200 \mathrm{~m}$ Gaussian filter was applied.

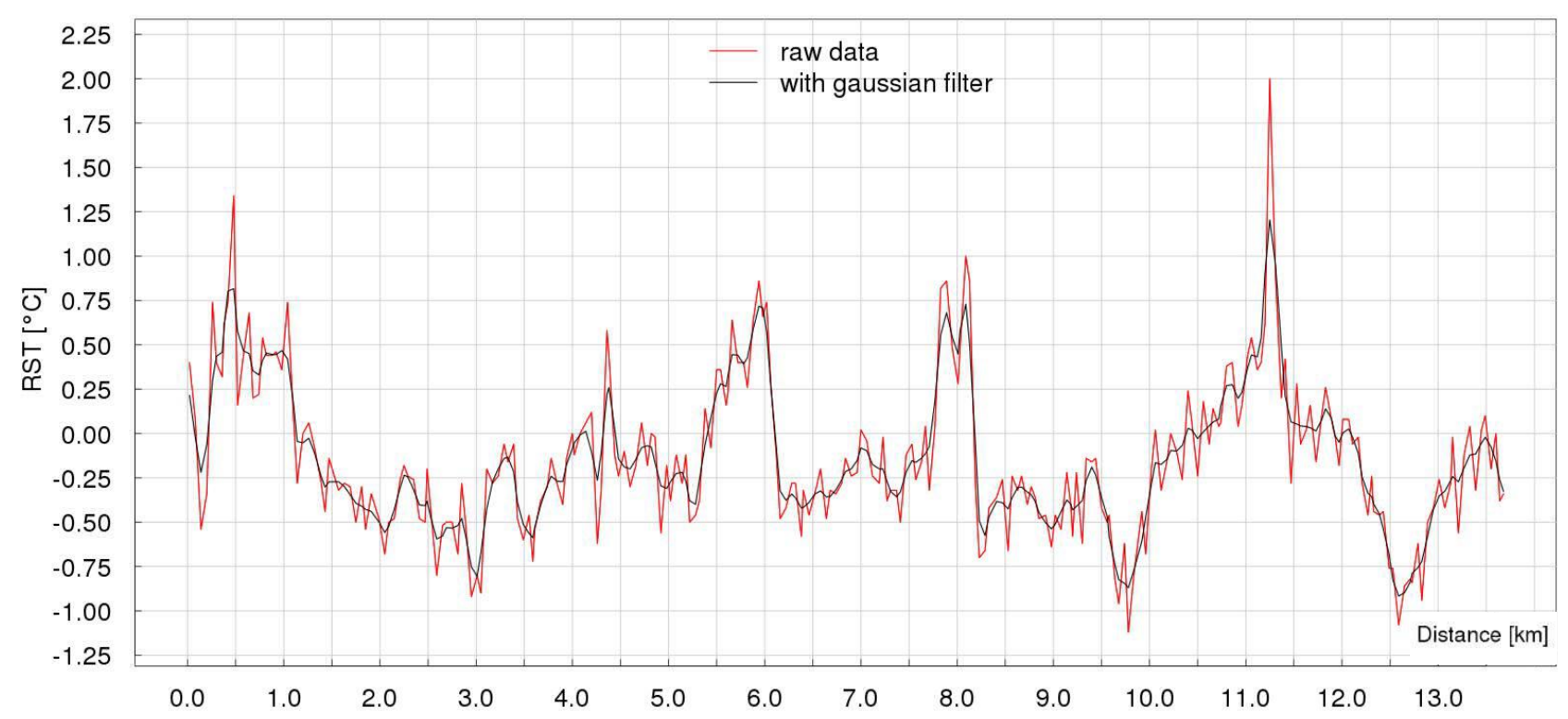

Figure 3. Example of application of a low-pass Gaussian filter to road temperature data collected via thermal mapping. 


\subsection{Processing stage: characteristic thermal fingerprint and spatialized forecasts}

For each route the acquired dataset of filtered fingerprint was used to define unique "characteristic" fingerprints for that route. "Characteristic" fingerprints were computed as follows (Figure 4). First, each single thermal fingerprint was referenced to RWIS stations via:

- the calculation of the difference $\varepsilon$ between the RST measured by the thermal mapping probe in correspondence of the static station located in the position $\mathbf{x}^{*}$ and the RST measured by the corresponding RWIS station;

- the removal of $\varepsilon$ from the thermal fingerprint;

- the calculation of the difference $\Delta$ between the RST value at point $\mathbf{x}$ along the route and the RST value at the station position $\mathbf{x}^{*}$.

Secondly, the historical dataset of $\Delta$ RST differences were compared point by point along the route by calculating the minimum and the mean $\Delta$ RST values. Two "characteristic" fingerprints were thus obtained: one made with minimum $\Delta$ RST values, and one made with averaged $\Delta$ RST values. With a statistically significant number of thermal fingerprints, the mean and the minimum characteristic fingerprints represent the most likely and the minimum RST departures from the station-measured RST, respectively. The use of the minimum $\Delta$ RST is precautionary as it tends to underestimate RST values and thus overestimate the likelihood of ice formation. This is in agreement with the approach adopted in CLEAN-ROADS system, that is, to inform road operators in advance about the possibility of ice formation, especially when there is no ice risk so that they can schedule other maintenance tasks. However, when a risk is present (although minimum), road operators have to be aware that a de-icing treatment could be necessary in the following hours and must pay attention. Their final decision is supported by an automatic alarms generation tool developed on top of the real-time measurements transmitted by the static RWIS stations ${ }^{1}$.

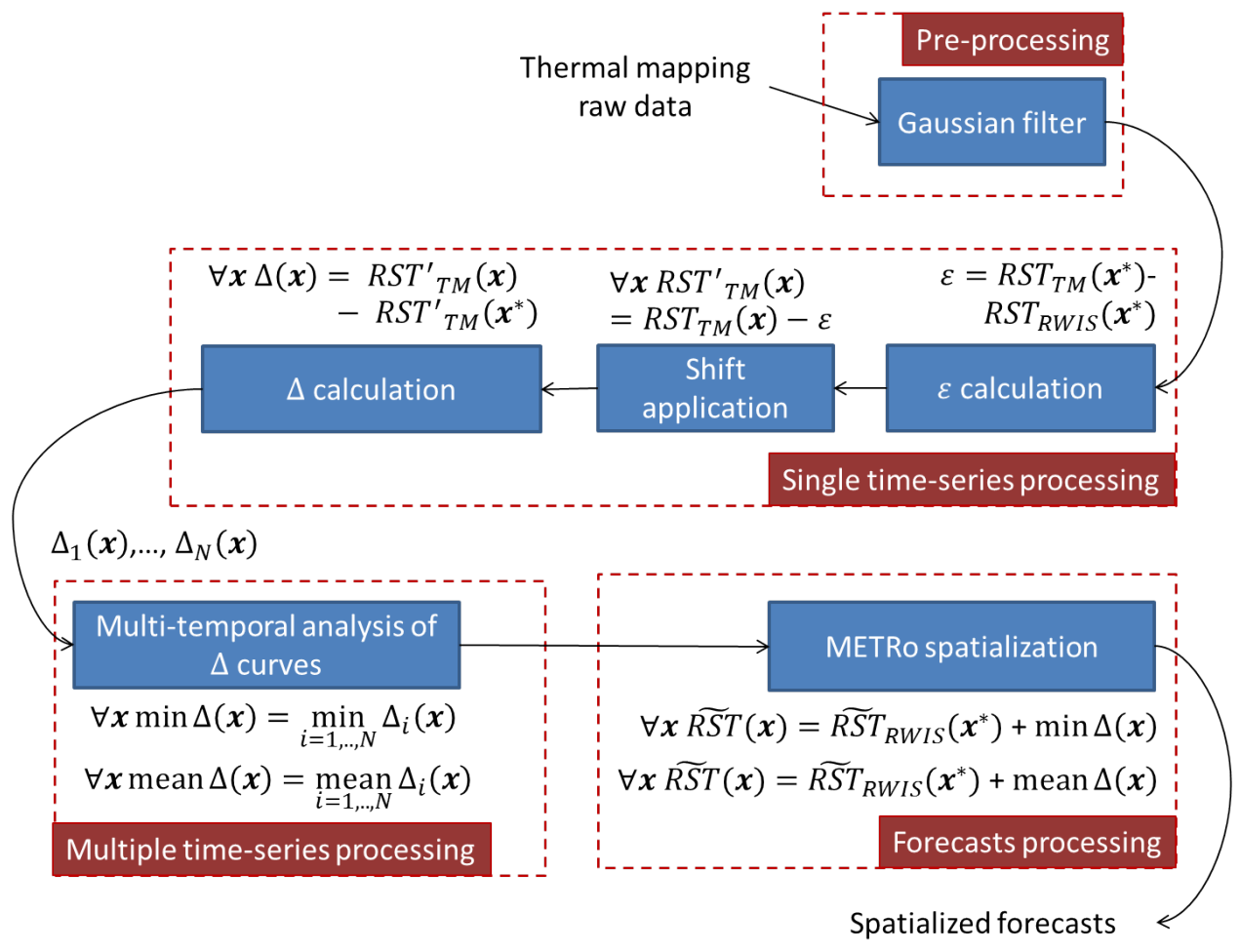

Figure 4. Methodology used in the study for the automatic processing of thermal mapping data.

Besides referencing, RSTs measured by RWIS stations were also used to predict overnight RSTs via METRo model ${ }^{3}$. Combined with road and atmospheric observations from RWIS stations, measured RSTs were used as initial conditions to run METRo and couple it with a meteorological numerical prediction model from the European Centre for MediumRange Weather Forecasts, ECMWF (T1279 high resolution atmospheric model, $16 \mathrm{~km}$ horizontal resolution, 12UTC run). The output is a site-specific forecast of overnight RST minima as expected at static RWIS station locations. The combination of METRo forecast with the "thermal map" of the study area, i.e. a $\Delta$ RST map showing how much warmer 
and colder RSTs would be along a route in relation to the RST at RWIS station point, were used to predict RSTs over the entire road network at selected times (20:00, 22:00, 24:00 local time).

\section{RESULTS AND DISCUSSION}

\subsection{Thermal mapping surveys characteristics}

The "Adige Valley" route is entirely located at an average height of $220 \mathrm{~m}$ above the sea level. Its asphalt composition is mixed: porphyritic in some sections and calcareous in others. It presents a 2-lane configuration with 9.000 vehicles running on average for day in winter season (Table 1). One static RWIS station is installed along this route, close to a countryside area.

Table 1. Classification of the "Adige Valley" route according to land uses and road-types.

\begin{tabular}{|c|c|c|c|}
\hline Section $\mathrm{n}$. & $\begin{array}{l}\text { From - to } \\
\quad[\mathrm{km}]\end{array}$ & Land use & Road peculiarity \\
\hline 1 & $0.0-1.5$ & Residential & Lavis Bridge from $\mathrm{km} 0.1$ to $\mathrm{km} 0.2$ \\
\hline 2 & $1.5-2.2$ & Industrial & Road is above an underground railway \\
\hline 3 & $2.2-6.7$ & Countryside & \\
\hline 4 & $6.7-8.2$ & Residential & \\
\hline 5 & $8.2-11.2$ & Countryside & Road runs parallel to Adige river \\
\hline 6 & $11.2-11.6$ & Residential & \\
\hline 7 & $11.6-13.7$ & Countryside & Road is north exposed and is shaded form mountains \\
\hline
\end{tabular}

Figure 5 shows thermal fingerprints for the "Adige Valley" route acquired under extreme conditions, after they had been filtered as described in the "Methodology" chapter.

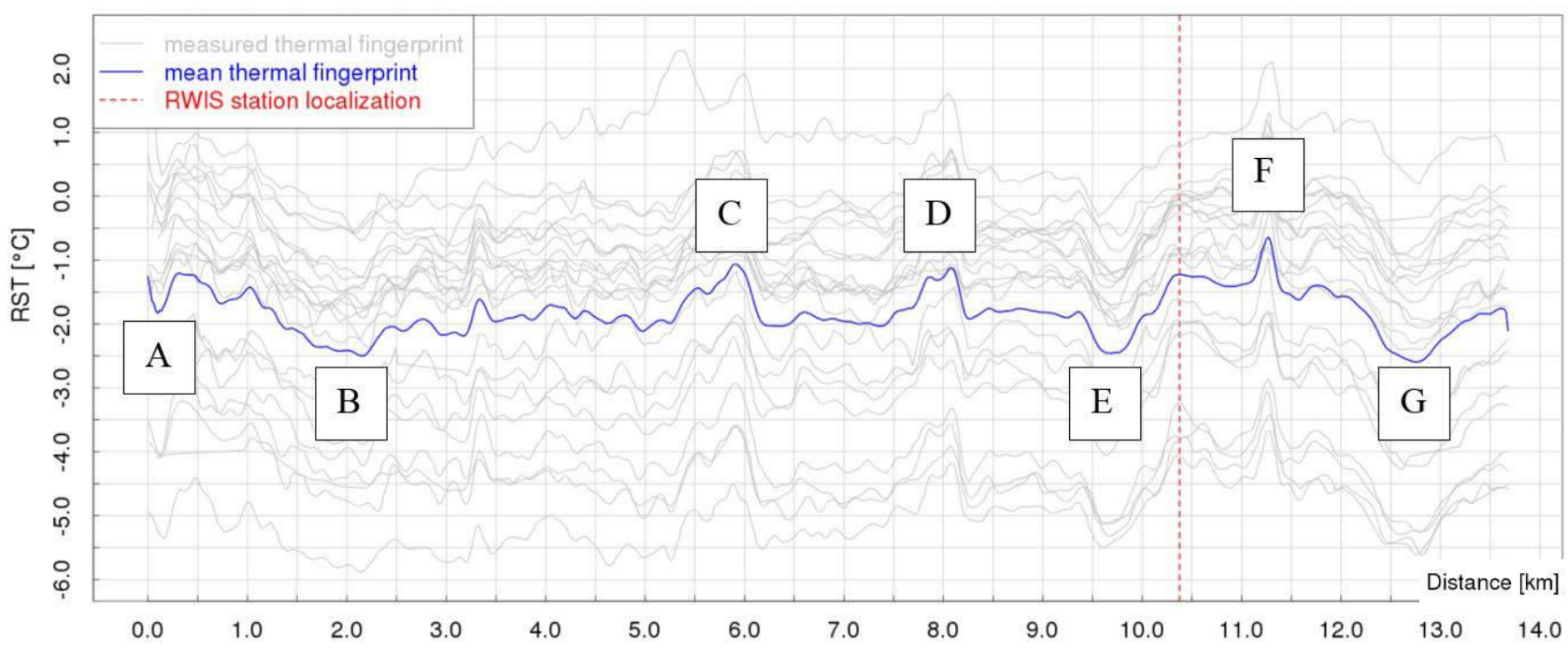

Figure 5. Thermal fingerprints for the "Adige Valley" route.

It also indicates the mean of all extreme thermal fingerprints and the location of the RWIS station installed along the route $(\mathrm{km} \mathrm{10.4).} \mathrm{Interesting} \mathrm{areas} \mathrm{are} \mathrm{pointed} \mathrm{out} \mathrm{on} \mathrm{the} \mathrm{mean} \mathrm{thermal} \mathrm{fingerprint} \mathrm{with} \mathrm{capital} \mathrm{letters} \mathrm{and} \mathrm{can} \mathrm{be}$ identified as follows: (A): Lavis bridge in a residential area; (B): road stretch above an underground railway in an industrial area; $(\mathrm{C})$ : road stretch in a countryside area near a rock face heated up on the south side by sun during the day; (D): road stretch in a residential area surrounded by buildings; (E): road stretch in a countryside area; (F): narrower road 
stretch in a residential area surrounded by tall buildings; $(\mathrm{G})$ : road stretch in shade and in a countryside area. A, B, E and $\mathrm{G}$ are cold spots, while $\mathrm{C}, \mathrm{D}$ and $\mathrm{F}$ are hot spots.

The "Valsugana Valley" route develops from a mountainous/hill area to a valley bottom and crosses residential, industrial, countryside and mountainous areas. The route starts at a height of $480 \mathrm{~m}$ above the sea level and reaches a height of $200 \mathrm{~m}$ above the sea level. Its asphalt composition is mixed: porphyritic in some sections and calcareous in others. It presents two different lane configurations, and the average daily traffic flux is about 43.300 vehicles for day in winter season (Table 2). One static RWIS station is installed along this route, close to a countryside area.

Table 2. Classification of the "Valsugana Valley" route according to land uses, road-types, lane configurations and traffic fluxes.

\begin{tabular}{|c|c|c|c|c|}
\hline $\begin{array}{l}\text { Section } \\
\text { n. }\end{array}$ & $\begin{array}{l}\text { From - to } \\
{[\mathrm{km}]}\end{array}$ & Land use & Road peculiarity & $\begin{array}{c}\text { Lane } \\
\text { configuration }\end{array}$ \\
\hline 1 & $0.4-2$ & Mountainous/hill & $\begin{array}{l}\text { Road runs parallel to Fersina river with Corona tunnel from } \mathrm{km} 1.6 \\
\text { to } \mathrm{km} 1.7\end{array}$ & 4 lanes \\
\hline 2 & $2-3$ & Mountainous/hill & Crozzi tunnel from $\mathrm{km} 2$ to $\mathrm{km} 3$ & 4 lanes \\
\hline 3 & $3-4.3$ & Mountainous/hill & Crozzi viaduct from $\mathrm{km} 3$ to $\mathrm{km} 3.6$ & 4 lanes \\
\hline 4 & $3.6-8.0$ & Mountainous/hill & $\begin{array}{l}\text { Road exposed to the Adige Valley with Ponte Alto tunnel from km } \\
4.3 \text { to } \mathrm{km} 4.6 \text { and with Laste tunnel from } \mathrm{km} 5.6 \text { to } \mathrm{km} 5.8\end{array}$ & 2 lanes \\
\hline 5 & $8.0-9.9$ & Industrial & Canova viaduct from $\mathrm{km} 9$ to $\mathrm{km} 9.7$ & 4 lanes \\
\hline
\end{tabular}

The dataset of extreme thermal fingerprints for the "Valsugana Valley" route and the corresponding mean thermal fingerprint are shown in Figure 6 after noise removal. The location of the RWIS station installed along the route is indicted ( $\mathrm{km} \mathrm{1.4)}$. Interesting areas can be identified as follows: (A): road stretch below an embankment; (B): bridge over the "Rio Farinella" with a stretch clear from trees; (C): "Corona" tunnel; (D): "Crozi" tunnel; (E): "Crozi" viaduct; (F): "Ponte Alto" tunnel; $(\mathrm{G})$ : road stretch exposed to the Adige Valley and sheltered by mountainside rocks; $(\mathrm{H})$ : "Laste" tunnel; (I): road stretch sheltered by mountainside rocks and (L): Canova viaduct. A, B, E and L are cold spots while $\mathrm{G}$ and $\mathrm{I}$ are hot ones. C, D, F and $\mathrm{H}$ are tunnels.

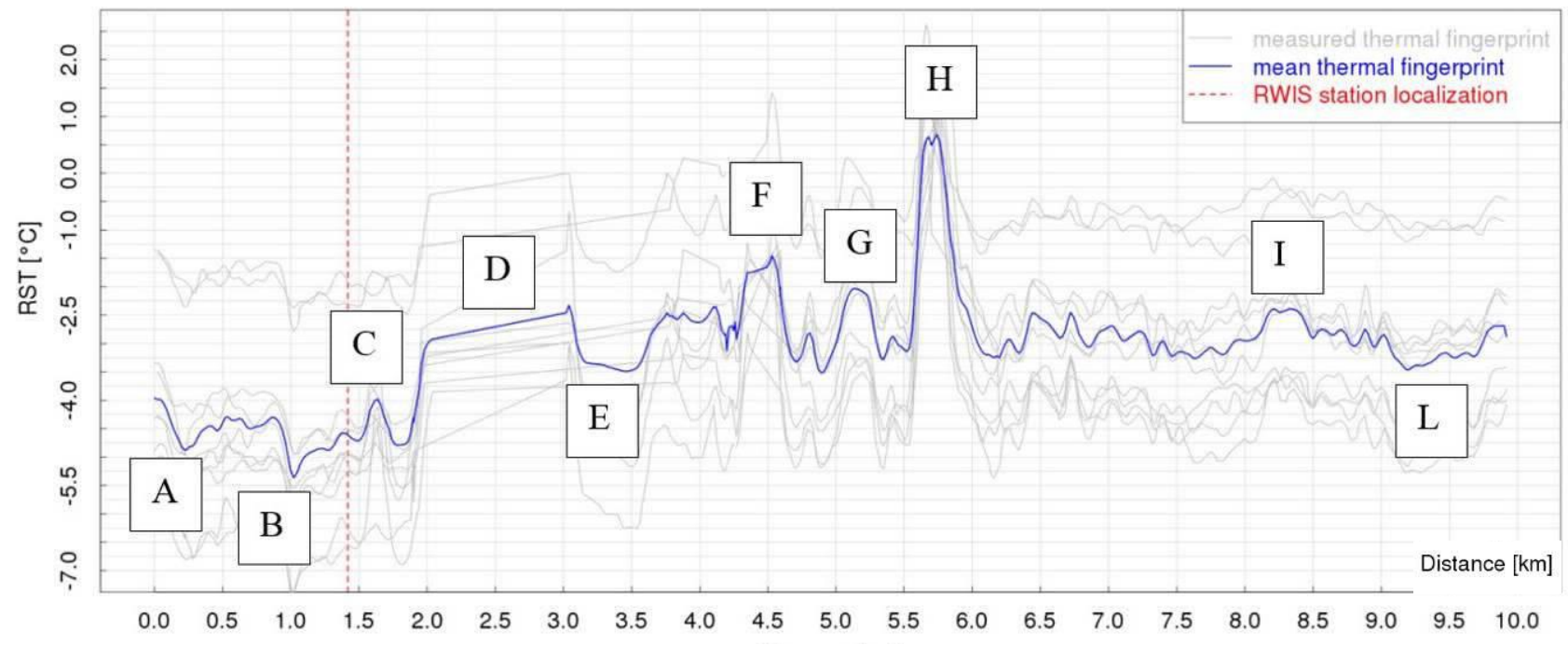

Figure 6: Thermal fingerprints for the "Valsugana Valley" route. 


\subsection{Spatialization model results}

For the "Adige Valley" route the minimum characteristic fingerprint is approximately $0.5^{\circ} \mathrm{C}$ lower than the mean characteristic fingerprint (Figure 7), with the exception of a cold spot after the RWIS station (km 12.75) that corresponds to a screened zone (Figure 6, G point). Here the difference between the two curves is in the order of $1^{\circ} \mathrm{C}$. For the "Valsugana Valley" route, the difference between the two curves is on average approximately $0.5-0.8^{\circ} \mathrm{C}$ (Figure 8 ).

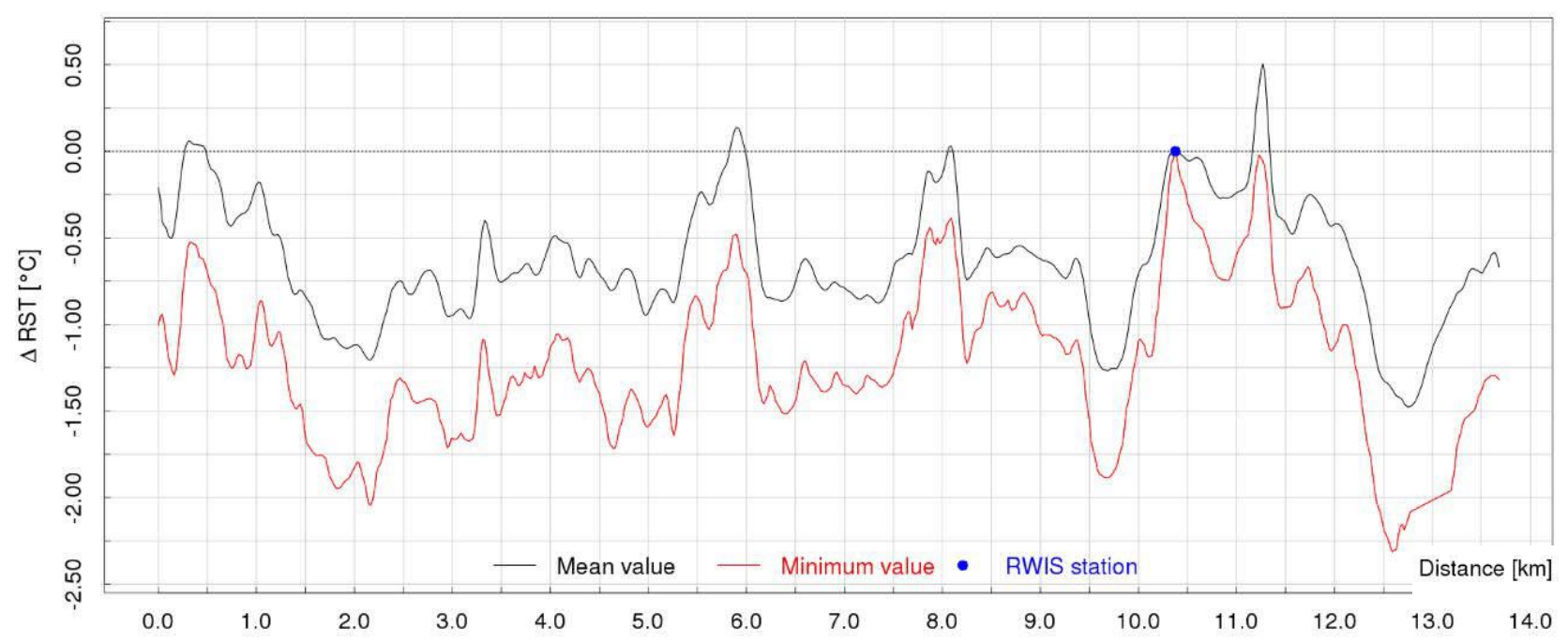

Figure 7: Minimum and mean values of $\Delta$ RST for the "Adige Valley" route.

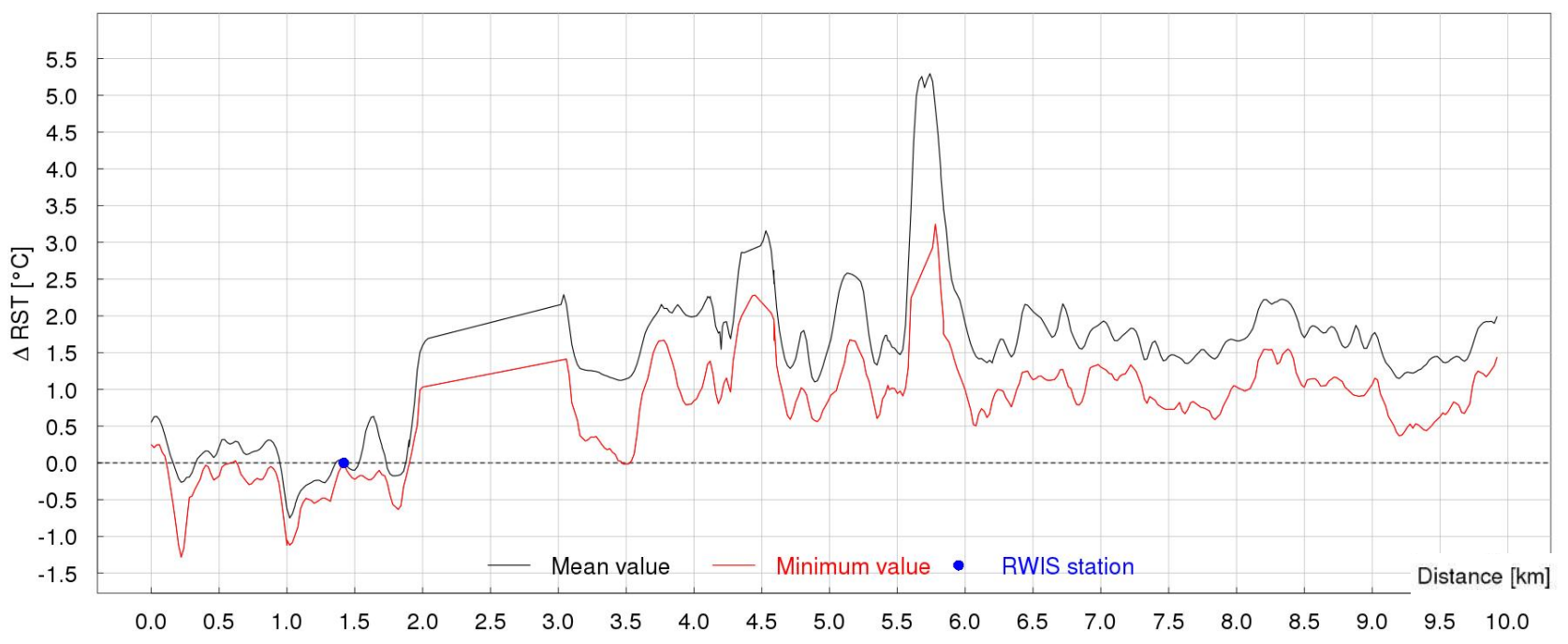

Figure 8: Minimum and mean values of $\Delta$ RST for the "Valsugana Valley" route.

To increase the statistically relevant number of thermal fingerprints considered in the calculation of the characteristic fingerprints, an extended definition of the extreme weather conditions was introduced. This includes surveys carried out when one of the two defining meteorological criteria described in Methodology (sub-section 2.3) was not fulfilled, i.e. a wind speed slightly higher than $2 \mathrm{~m} / \mathrm{s}$ or a cloud cover slightly larger than 1/8. In winter seasons 2014-2015 and 20152016, 23 and 16 "extended" extreme thermal fingerprints were collected along the "Adige Valley" route and the "Valsugana Valley" route, respectively. A comparison between characteristic fingerprints acquired under extreme conditions and under "extended" extreme conditions is shown in Figure 9. The difference is not significant. The temperature profile along a particular thermal mapping route is usually relatively similar in pattern, also under different weather conditions ${ }^{7}$. Different meteorological conditions that are uniform on the whole route affect the amplitude of the relative temperature differences between cold and warm sections but do not alter the main pattern of the thermal 
fingerprint. For this reason, the characteristic fingerprints obtained under "extended" extreme meteorological conditions was adopted for the spatialization procedure.

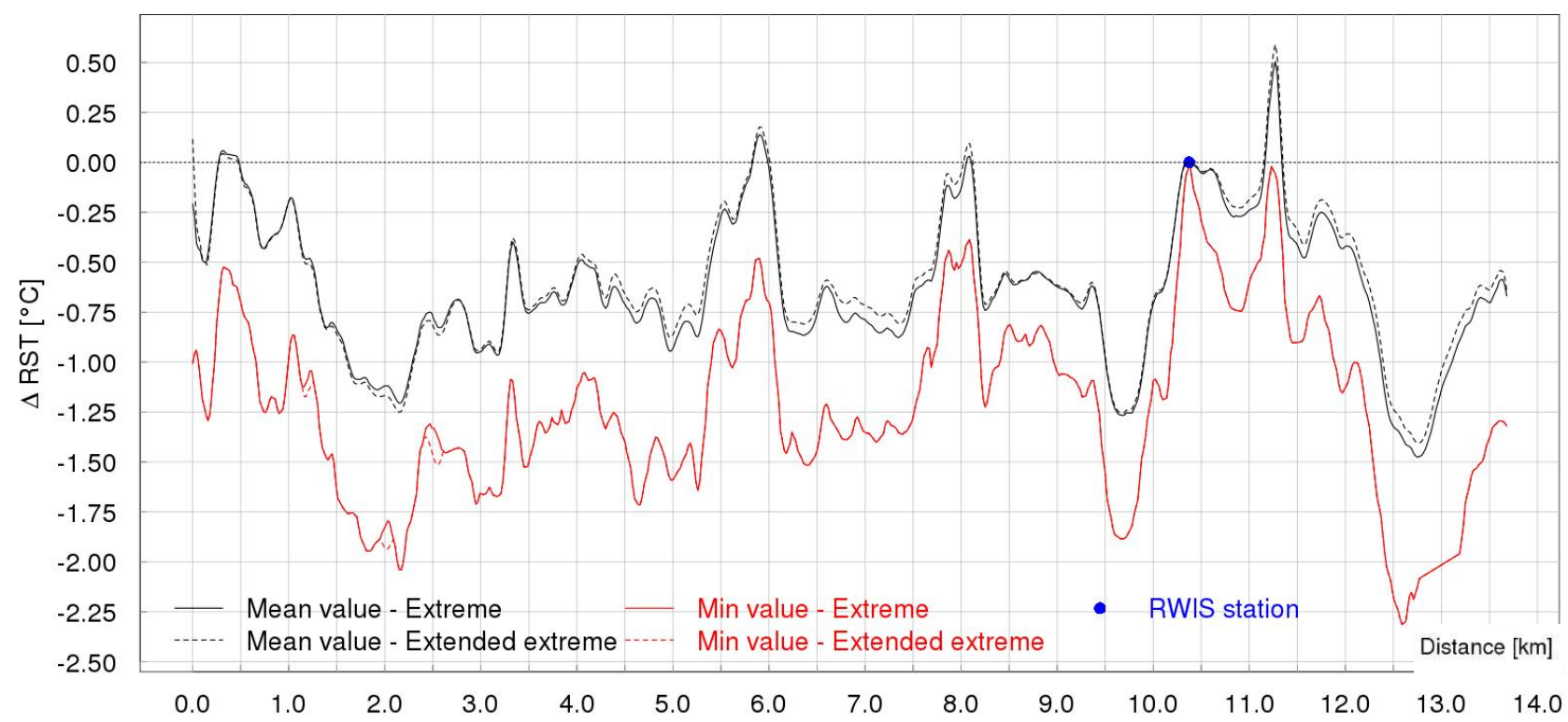

Figure 9: Comparison between minimum and mean values of the $\Delta$ RST for the "Adige Valley" route under extreme conditions and "extended" extreme conditions.

Spatialization was applied to the RSTs forecast by the METRo model at the points where static RWIS stations are installed. Specifically, minimum RSTs were first predicted automatically every night at the reference sites through METRo. Forecast minimum RSTs were then extended to the entire route by keeping into account the location of cold and hot spots as indicated by the mean/minimum characteristic fingerprint. Figure 10 shows the result of the first example in the Alpine area of a predicted "thermal map". METRo-predicted RSTs at the RWIS station on the "Valsugana Valley" route for February 6 ${ }^{\text {th }}, 2016$ are spatialized over the entire road. Using a color code, road stretches where RSTs are forecast to go below $0^{\circ} \mathrm{C}$ are indicated in blue, road stretches with forecast RSTs between $0^{\circ} \mathrm{C}$ and $2^{\circ} \mathrm{C}$ are indicated in yellow, and road stretches with forecast RSTs above $2^{\circ} \mathrm{C}$ are indicated in red.

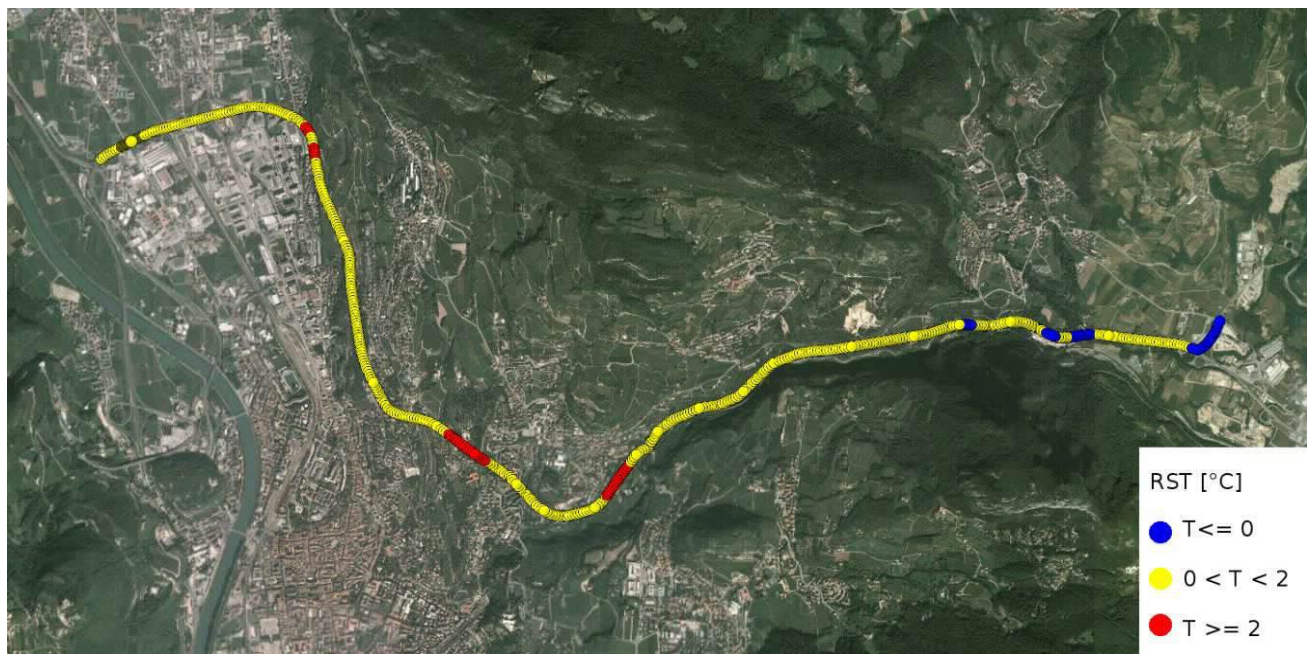

Figure 10: Example of the spatialization for RST minimum values predicted by the METRo model (24:00 run, local time) along the "Valsugana Valley" route on February 6", 2016.

An evaluation was performed on the quality of the METRo prediction. In Figure 11 RSTs measured via thermal mapping along the "Adige Valley" route and RSTs predicted by METRo model for the same route on January $26^{\text {th }}, 2016$ are 
compared. Forecast RST minimum values are observed to well reproduce RST measured values. Cold spots can be identified and are in agreement with those described in the previous Section. The mean characteristic fingerprint was evaluated on the basis of the "extended" extreme thermal fingerprints acquired before $26^{\text {th }}$ January. Those fingerprints were used as training dataset, i.e. to predict reasonable values for the $\Delta$ RST correction. The thermal fingerprint acquired on $26^{\text {th }}$ January was used as a testing dataset. Figure 11 shows that RSTs measured that day stayed between mean and minimum forecast RSTs along the entire route except for the stretch between C and D hot points where measured RSTs were slightly smaller than the minimum forecast RSTs. This result encourages the use of the minimum characteristic fingerprint to avoid possible local underestimation of RSTs.

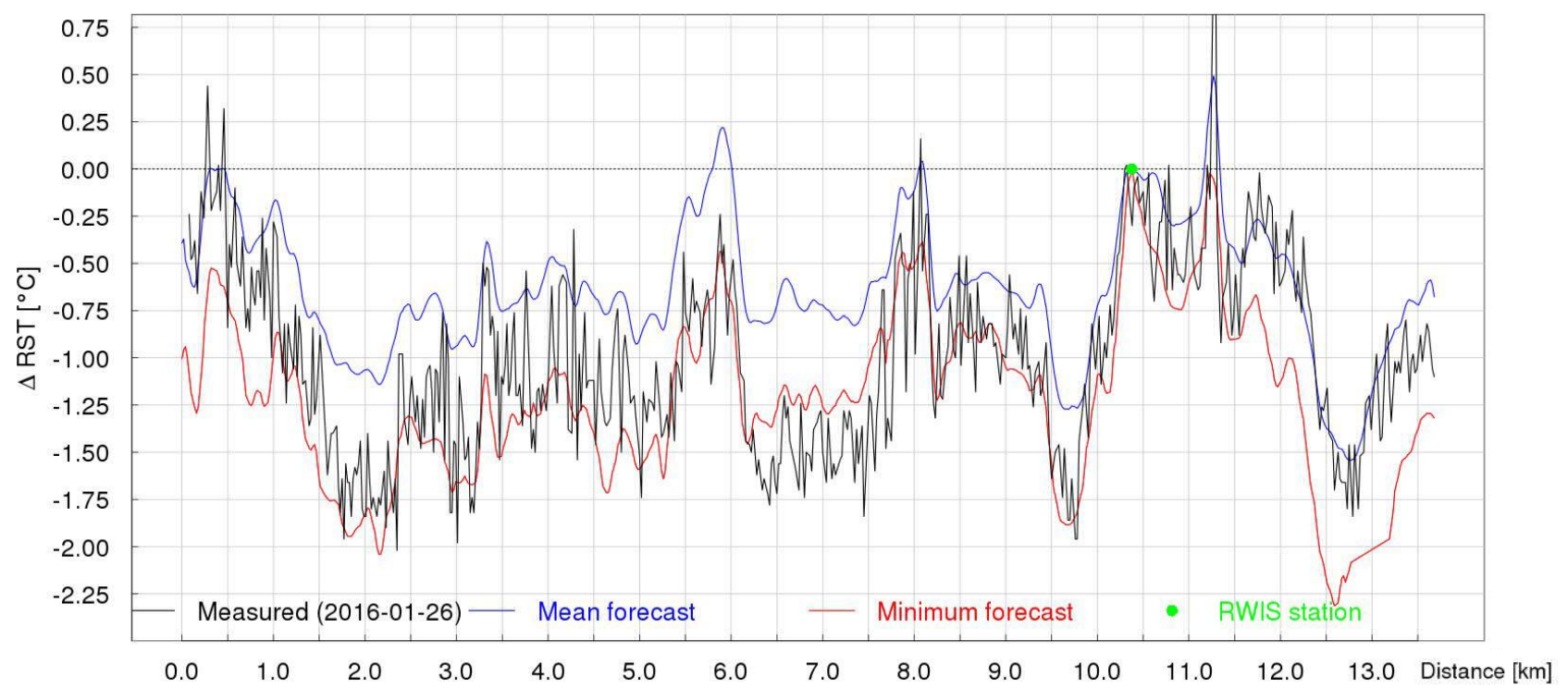

Figure 11: Comparison between forecast (mean in blue; minimum in red) and measured (black) RST values for the "Adige Valley" route on January $26^{\text {th }}, 2016$. The location of the static RWIS station is plotted for reference.

\section{CONCLUSIONS}

This paper presents thermal mapping as a novel helpful procedure for road winter maintenance. The acquisition of RSTs via an infrared thermometer mounted on a vehicle permits to identify the unique pattern and distribution of warm and cold sections along a road. In this study we demonstrate that knowing such a "temperature fingerprint" is the key to conscious road maintenance behaviors. Thermal mapping data have first been acquired along two selected routes in the Italian Alps in extreme meteorological conditions. We have found that RST is not spatially homogeneous and cold spots are observable due to topography, orography and road-related variables. As suitable conditions for ice formation are likely to occur at cold spots, we have then combined the information from temperature fingerprints with METRo forecast model in order to predict those spots in space and time. Forecasts of minimum RSTs have been provided daily for the selected routes and sections with predicted RST minima below freezing have been displayed accordingly. We have thus obtained a forecast "thermal map" in a complex terrain area, i.e. a mountainous location where RST variations along a road may put at risk travellers' safety. With RST data soon been provided by alternative equipment such as car on-board sensors, the future research challenge will be to combine RST data from thermal mapping with RST data from a variety of measurement techniques and tools. The ultimate aim is to provide road engineers and users with reliable information on the current and future conditions of a road network.

\section{ACKNOWLEDGEMENTS}

The authors would like to acknowledge the European Commission and the LIFE+ program for the financial support, and the RSCy2016 organizing committee for the possibility given to present the CLEAN-ROADS project to the international remote sensing and geo-information community. 


\section{REFERENCES}

[1] Pretto, I., Merler, G., Benedetti, G., Tschurtschenthaler, T., Apolloni, R., Cavaliere, R. and Seppi S., “Addressing the environmental impact of salt use on the roads: the CLEAN-ROADS project", SIRWEC 2014 conference proceedings, ID:0019 (2014).

[2] Marchetti, M., Chapman, L., Khalifa, A. and Buès, M., "New Role of Thermal Mapping in Winter Maintenance with Principal Component Analysis", Advances in Meteorology, vol. 2014, Article ID 254795, 11 pages (2014).

[3] Crevier, L.-P. and Delage, Y., "METRo: A New Model for Road-Condition Forecasting in Canada", Journal of Applied Meteorology, 40, 2026-2037 (2011).

[4] Shao, J., Swanson, J.C., Patterson, R., Lister, P.J. and McDonald, A.N., "Variation of winter road surface temperature due to topography and application of Thermal Mapping", Meteorological Applications, 4, 131-137 (1997).

[5] Ramakrishna, D.M. and Viraraghavan, T., "Environmental Impact of Chemical Deicers - A Review", Water, Air, and Soil Pollution, 166, 49-63 (2005).

[6] Sarro, P.M., "Integrated Silicon Thermopile Infrared Detectors", Delft University Press (1987).

[7] Shao, J., "Fuzzy Categorization of Weather Conditions for Thermal Mapping", Journal of Applied Meteorology, 39, 1784-17 (1999).

[8] Gustavsson, T., "Thermal mapping - a technique for road climatological studies", Meteorological Applications, 6, 385-394 (1999).

[9] Shao, J. and Lister, P.J., "Data filtering for thermal mapping of road surface temperatures", Meteorological. Applications, 2, 131-135 (1995). 